\title{
FORMAS DECALCANDO FORMAS: \\ A MATERIALIDADE DO TRÁGICO
}

Bárbara Del Rio Araújo

RESUMO: Este trabalho pretende destacar a materialidade do fenômeno trágico a fim de entender a especificidade histórica desse elemento estético, ainda que muitas vezes a crítica e a filosofia o tenham associado ao destino humano, às forças ocultas e irracionalistas da natureza. A versatilidade dos gêneros literários e a tragicidade produzem significados culturalmente e são concretizações das relações sociohistóricas, forma base das diferentes áreas da vida espiritual. $A$ sistematização do ponto de vista aqui abordado em torno do objeto contará com a referência teórica de Benjamin, Hegel e Lukács, cujo raciocínio implica em entender a totalidade das relações de produção da sociedade, a base real onde erige a superestrutura a qual corresponde formas definidas da vida social e intelectual. Nesse imbróglio, não é a poética dos gêneros ou a consciência dos homens que determinam a existência do trágico, mas a existência social que sobredetermina as suas diferentes configurações.

Palavras-chave: Materialismo; Gêneros Poéticos; Trágico.

\section{INTRODUÇÃO}

Discutir as conexões entre arte e sociedade é algo recorrente e de certo modo antigo, mas entender a formalização dessa relação, a determinação de suas estruturas é algo inovador e muito complexo. Pensando nisso, parte da crítica brasileira, nomes como Antonio Candido e Roberto Schwarz, se dedica a revelar as implicações sociológicas na arte a fim de entender um princípio generalizador que una ficção e realidade, tentando determinar o lugar da realidade dentro da ficção e o lugar da ficção dentro da realidade.

Antonio Candido, por exemplo, analisa a construção do poema "Caramuru", do Frei Santa Rita Durão, propondo mostrar como a estrutura fixa da épica leva em consideração a realidade e a variação histórica, sendo representativa do espaço nacional dentro de uma tradição consagrada. Em uma busca romântica de valorização, o poema funda o mito nacional e, mesmo sem a independência política e a consciência de uma literatura brasileira, reflete sobre três momentos importantes: a colonização, a natureza e os índios. 
Interessante ainda é destacar a ambiguidade dessas instâncias, organizadas pelo princípio estrutural religioso, de modo a ver uma colonização como iniciativa portuguesa e ao mesmo tempo justificação do brasileiro para a consciência de sua individualidade; uma natureza como visão do paraíso e apenas segmentos da paisagem; o índio como bondade e ao mesmo tempo como um autóctone bárbaro.

Nesse imbróglio, a obra de Durão constitui uma visão particular do gênero épico, aliás trata de uma adaptação em que se pode ver o elogio e a acentuação do nativismo e nacionalismo, característico ao modelo da Epopeia, mas também a expressão do triunfo do colonizador, processo de catequização e conquista portuguesa na América. No complexo estético-formal, a estrutura se abre ao elemento novelístico e exótico, podendo ali constar os germes para o pré-romance indianista. Nesse aspecto, a filiação e fuga do modelo são representativas do lastro histórico, revelando que a significação da obra literária está sim relacionada ao padrão formal a que ela pertence, mas, sobretudo como essa orientação estética se movimenta frente a realidade:

Durão quis mostrar, ao contrário, que a civilização se identificava ao catolicismo e era devida ao catequizador, - em particular ao jesuíta. E que a nossa história se explicava, de um lado, como incorporação progressiva do aborígine a esta ordem de crenças e práticas; de outro, como esforço do português para manter a ortodoxia, contra protestantes franceses e flamengos. (...)

Trata-se, portanto, de uma epopéia eminentemente religiosa, antipombalina, em que até na forma o autor se mostra passadista, ao repudiar o verso branco, tão prezado pelos seus contemporâneos, para voltar aos processos camonianos. Isto, é claro, não impede que sofra influências do seu tempo, inclusive as que o levam a suprimir quase completamente o maravilhoso. (CANDIDO, 1976, p.177)

Nessa seara do amalgamento entre a estrutura fixa literária e a irrupção da estrutura histórica, "Caramuru" tem um duplo aproveitamento tanto da epópeia quanto do romantismo. Assim, Durão se inscreve na tentativa de criar uma tradição brasileira que dialoga com o modelo literário cultuado. Tratase assim de um aproveitamento do padrão instituído e da reorganização do mundo da arte, em que o escritor aproveita o material, conforme um princípio de organização adequado à situação literária dada, que mantém a estrutura da obra.

Pode-se dizer que a análise empreendida por Candido persegue um balanceio entre os gêneros literários e a vida. O processo adaptação histórica dos gêneros é, pois, a pauta em questão. Nessa discussão, é inevitável a passagem pela Poética aristotélica, que empreende a tentativa de definir, organizar e caracterizar os textos literários. De modo categórico, Aristóteles define os limites para o Épico e o Dramático, procurando demonstrar o conteúdo e a forma desses textos. Nisso, ocorre a prescrição das estruturas 
num estudo de fundo e de fôrma. Entretanto, a acuidade da verossimilhança não escapa ao filósofo, fazendo com que se preocupe sobre como a configuração interna, autônoma, capta representa o mundo exterior.

Em Poética, Aristóteles didaticamente expõe como ocorre a criação da verossimilhança na arte e, especificamente em relação à tragédia, argumenta que é mimética por excelência, uma forma específica de mimesis que visa atingir o espectador pelo efeito catártico. A organização da encenação e o mito tem a função de estabelecer contemplação, conhecimento e reconhecimento das coisas como elas são, como foram ou como deveriam ser. Nesse aspecto, o referente exterior está em diálogo com a construção através dos meios, objetos e modos. O conceito aristotélico de mímesis, nesse aspecto, não é cópia da realidade, mas poieis, uma representação que resulta de um processo específico de construção, em que a techne imita os métodos e processos da natureza-physis; o resultado disso é a constituição imanente entre forma e matéria constitutiva tanto das substâncias sensíveis quanto dos artefatos. Dessa maneira, com relação à técnica artística, garante-se a autonomia, um conteúdo específico que não é dependente da referência com as coisas da realidade, mas que mantém semelhança com o mundo, sem que a ele seja subordinado.

Isto posto, por maior que fosse o esforço em definir o que seria lírico, dramático ou épico, havia obras teatrais consideradas não dramáticas e poesias pouco líricas. A ideia de que não se poderia por uma etiqueta nas composições e a tentativa de valorizar a liberdade do poeta se tornavam explícitas, sobretudo na modernidade e com a ascensão do romance moderno, que fugiu às convenções e foi capaz de reunir e parodiar os outros gêneros. Assim, a combinação se mostra ilimitada e muitas vezes imprevisível, revelando que todas as manifestações podem combinar entre si, o que faz com que seja importante a pesquisa histórica, a qual refuta o estancamento poético e adere ao estudo interpretativo de cada obra em sua especificidade:

Formamos do substantivo drama, o adjetivo dramático. Dizer que um drama é dramático é evidentemente uma tautologia. Um drama é uma peça teatral. Toda peça teatral é dramática? Ainda se diria aqui: não! Existem conhecidos dramas líricos. Bertolt Brecht toma a si a criação do "drama épico". E o que se dá com a epopéia? Denomina-se epopéia uma longa narrativa em versos. Toda longa narrativa em versos é épica? (...) Nem toda narrativa em versos é épica. Um romance não é uma narrativa em versos, portanto não é uma epopeia, mas é ainda assim uma obra épica. (STAIGER, 1997, p.184)

Observa-se que os termos épico, lírico e dramático passam, com o tempo, a ter prioritariamente a função adjetiva, multiplicando-se na caracterização das obras, sendo impossível de se apreender em sua unidade definidora. Abandona-se, nesse sentido, a ideia de pureza na análise dos textos literários, ideia essa que é já negada no fundamento da linguagem e nas 
alterações do uso linguístico. Tem-se a conclusão que qualquer obra autêntica participa em diferentes modos dos três gêneros, restando a separação e classificação à propedêutica antiga de se ensinar literatura.

Nesse âmbito, pode-se dizer que estamos nos aproximando da reflexão contemporânea sobre forma literária, síntese profunda do movimento histórico, dispensada do registro documentário e da filiação a modelos fixos, mas capaz de trazer a mimese na composição, organizando o que na realidade parece disperso e incompreensível. Trata-se de uma análise guiada pelo senso materialista e não pelo cunho tradicionalista de tradição, já que consegue captar as especificidades adaptativas:

O instante de expressão nas obras de arte não é, porem, a sua redução ao seu material enquanto algo de imediato, mas extremamente mediatizado. As obras de arte tonam-se aparições de um outro, quando o acento incide sobre o caráter irreal da sua realidade. (...) O instante da aparição das obras é a unidade paradoxal ou o equilíbrio do que se esvanece e do que se preserva; são tanto imobilismo quanto dinamismo (ADORNO, 1970, p.97)

\section{DESENVOLVIMENTO}

Instaurando um sistema de reflexão, os gêneros literários e a tradição neles fixadas como modalidade permanente de expressão são retomados e providos de historicidade de modo que as categorias poéticas se tornam dialéticas, assimilando o processo presente. Percebe-se, então, que as configurações estéticas não são plenamente universais, sendo específicas de uma cultura e de um processo histórico. Com o trágico, isso não é diferente. Advindo da tragédia, é preciso compreender como dela o fenômeno escapa de modo a dar conta do mundo moderno.

Vernant assim como Lesky, através de uma análise minuciosa das peças, esclarecem que o trágico, quando relacionado à tragédia representou uma época específica, quando a linguagem do mito estava em declínio dado à realidade política na cidade. Nesse aspecto, o trágico foi a representação de um tempo já decorrido, mas que ainda está presente na vida, situando-se entre dois mundos. A ambivalência desse lugar reflete na questão humana, especificamente no herói, que pertence a uma tradição mítica, traduzindo valores coletivos, ao mesmo tempo em que se encaminha para um cenário imposto pela Tebas democrática. (VERNANT, 1977, p.7)

Apesar de não elaborar uma discussão aprofundada sobre o trágico e como ele se relaciona à concepção de mundo vivida, Aristóteles define a tragédia como a "imitação de acontecimentos que provocam piedade e terror e que ocasionam a purificação dessas emoções", nisso acaba por noticiar aspectos do sistema cultural, expondo, na dramatização da falha trágica e consequentemente na compaixão e no terror, o elemento moral que cerca aquela sociedade e aquela forma de arte. (ARISTÓTELES, 1985, p.248). A 
tragédia sempre revelou a dignidade da queda dos heróis, que provém dos mitos, mas também sugestionava a delimitação da ordem social a que pertenciam. Nesse aspecto, mito e história são fundantes desse gênero e compõe de modo dinâmico as ações e a vida das personagens, que conscientes marcham para o degredo. A forma dramática da tragédia incorpora de maneira única a história, o tempo presente, o mito e a reação ao mito (WILLIANS, 2002, p.37). O acontecimento trágico, para além do efeito didático-educativo da tragédia, concebe a representação da cultura, reunindo antagonismos no plano da história social, da racionalidade e da mitologia, a revelar as contrições do homem e da sociedade que o cerca.

A cultura grega é marcada por uma extraordinária rede de crenças que liga instituições, práticas e sentimentos - e não por princípios sistemáticos abstratos a que chamaríamos de uma teologia trágica. É um lugar comum, no sistema grego, abstrair a necessidade, colocando suas leis acima do arbítrio humano. Mas os arbítrios dessa necessidade, até onde ela pode ser generalizada, são revelados em ações reais, não conhecidas de antemão ou de forma genérica. Deste modo, existe um processo de reformulação dos mitos, transformando-os em ações dramáticas específicas com inevitáveis conexões com as experiências do momento presente. Assim, aquilo que se presta a imitação na tragédia é resultado singular de um processo - uma forma dramática específica. Ela não é uma realização estética ou técnica que pode ser isolada; ao contrário, ela está firmemente enraizada numa estrutura de sentimento precisa, situada historicamente:

\footnotetext{
É aqui que o sistema moderno se equivoca mais redondamente na interpretação das peças. Tendo abstraído uma necessidade universal, posiciona em seu interior e contra ela, indivíduos que experimentam o sofrimento e que resumem a figura do herói trágico. O motivo principal da ação é visto então como isolamento desse herói. Mas, de forma única, esta é uma tragédia com coro. As específicas e variadas relações entre o coro e os atores formam suas relações dramáticas reais. (WILLIANS, 2002, p.37)
}

Percebe-se que na coletividade do mundo grego, a individualidade se mostra en gérmen, e, com a sua dissolução, a prática da tragédia estabeleceria novas conexões, assumindo os temas históricos enquanto trágicos. Na secularização, por exemplo, mostrou a questão do comportamento, mais do que a condição de um erro metafísico, relacionando-o diretamente ao homem, com a sua ação e prosperidade econômica. Notamos, então, a interiorização do processo alicerçada a condição social; além do modo de lidar e aprender com o sofrimento, que passa a ser tão importante quanto vivenciá-lo (HAUSER, 1994, p. 86-87).

O isolamento do herói, por meio do confinamento e da posição social, na associação trágica ocorre, mas é importante vê-lo como progresso de uma cultura: na medida em que a cultura se modifica e o percurso histórico-social 
ganha novos contornos, o coro, elemento da forma dramática, vai se enfraquecendo a ponto de ser descartado. Nesse aspecto, a tensão entre a experiência coletiva e a individual se rarefaz e o conflito se torna internalizado: o homem começa a ter a experiência de si mesmo enquanto agente autônomo em relação às forças religiosas, mas suscetível às demandas socioeconômicas, podendo mais ou menos dirigir seu destino pessoal. Nesse registro, configuram-se diferentes visões sobre o trágico na modernidade a partir da relação dialética entre indivíduo e sociedade. Aliás, essas visões se cristalizam como formas estéticas a representar a realidade: o mundo e a vida aqui permanecem e são acolhidos e configurados. $E$ as formas jamais poderão por si mesmas num passe de mágica dar vida a algo que nelas não se encontre. (LUKACS, 2000, p.45)

No mundo grego, a vontade não se coloca, a significação psicológica é indecisa, e paira uma consciência social numa condição histórica determinada. O herói é formado e fixado em hábitos coletivos se constituindo conforme as disposições, sendo improvável comportar-se de outro modo, pois assimila o que é externo como espontâneo. No mundo moderno, as personagens são dramatis pernonae, que devem buscar por si próprio o seu destino, isto é, nasce na solidão, em meio a outros solitários, não encontrando ressonância adequada. Aliás, o problema da solidão é essencialmente moderno, quando não há a simples embriaguez de uma alma aprisionada pelo destino e convertida em canto, mas também a configuração do tormento de uma criatura condenada ao isolamento que anseia pela comunidade. (LUKACS, 2000, p.43)

Nessa perspectiva, é necessário entender que o trágico moderno é capaz de reunir a dimensão estética e filosófica a ponto de pensar o indivíduo e o mundo que o cerca e a representação. Nesse aspecto, há uma totalidade vislumbrada, ainda que essa não seja plena, já que na vida existe a independência relativa a cada ser vivo autônomo em relação aos vínculos que apontam para mais além e a imprescindibilidade de tais vínculos. Assim, ainda que o trágico contemple o homem e seu destino, essa subjetividade:

arranca um pedaço da imensa infinitude dos sucessos do mundo, empresta-lhe uma vida autônoma e permite que o todo do qual ele foi retirado fulgure no universo da obra apenas como sensação e pensamento dos personagens apenas como o desfiar involuntário de séries causais interrompidas apenas como espelhamento da realidade que existe por si mesma. (LUKACS, 2000 p.48)

A perspectiva materialista de relacionar o trágico à condição históricasocial é necessária para se evitar o estudo parcial do fenômeno; a visão trágica do herói não é a condenação da existência do homem, mas a relação entre o erro, a moral e a crise histórica. O trágico, sob esse viés, recusa a normalidade do sofrimento, o deleite metafísico da criação e dá a ela lastro ontológico, mostrando a relevância do percurso político e histórico na estetização do 
sofrimento. O caráter objetivo da história se impõe e as ações trágicas estão nos momentos de conflito do desenvolvimento social e humano. Nesse aspecto, o processo espiritual que leva em conta o sujeito é retomando e transformado na descrição de um processo social, que lhe sobredetermina.

\title{
CONCLUSÃO
}

\begin{abstract}
O sentido do trágico é sempre culturalmente e historicamente condicionado, mas o processo artístico em que uma específica desordem é vivenciada e resolvida é mais difundido e importante. (...) As ideias de ordem tem importância criticamente apenas quando estão em solução dissolvidas em obras específicas como precipitados (WILLIAMS, 2002, p.77)
\end{abstract}

Percorreu-se nesse trabalho a discussão sobre a flexibilidade dos gêneros em relação à realidade moderna e deste modo vislumbrou-se a discussão sobre a obra literária enquanto forma e representação. Nessa seara, destacou-se o tema da materialidade do trágico, ratificando que não se entende esse fenômeno como predeterminação de um movimento apenas espiritual ou pessimismo absoluto: isso, aliás, é um preconceito decadente, que mostra o homem minado diante de suas aspirações. Para a visão aqui desenvolvida, a relação trágica entre indivíduo e a história representa a concreta e sempre renovada luta entre o velho e o novo. Acreditando nas contradições do homem como parte de uma infraestrutura social, relutou-se contra o estudo do trágico no sentido hermético e também no sentido religioso. Eles comprometem a percepção de que o conceito e as ideias estão ligados ao mundo dos fenômenos. É preciso elucidar que o trágico é uma representação da estrutura empírica, sem que seja dela uma imitação. Nesse aspecto, compreende-o como uma configuração estética e filosófica de um aspecto mundano que tem, pois, as suas diferentes formas, mas nenhuma delas se aparta completamente da relação com a realidade.

Discutir a representação do trágico é se referir à configuração formal, evidenciando a relação entre estrutura estética e processo social. Trata-se, aliás, de entender que a arte concentra e revela a trama contida na realidade. Nesse aspecto, o conceito subjacente a sua forma pode expor a discussão metafísica espiritual, o intento intuitivo e inventivo, mas não se isola, ao contrário, sedimenta o acontecimento histórico. A natureza da criação absorve o dado empírico e o reconstrói, fazendo dele conteúdo social sedimentado. Os impulsos e as determinações externos são transformados e passam a se articular no plano artístico. 


\section{FORMS PRODUCE FORMS: THE TRAGIC MATERIALITY}

\section{Abstract}

This paper aims to detach tragic phenomenon's materiality in order to understand the historic specificity of this aesthetic element, although many times the critic and the philosophy associate it to the human destiny, to the hidden and irracionalist nature strengths. The literary genres versatilities and the tragicity produce purports culturally and are concretions from socio-historical relations, base form of different spiritual life areas. The systematization of this viewpoint around the object will use the theoretical reference by Benjamin, Hegel and Lukács, whose reasoning imply comprehend the totality of production relations from the social and intellectual life. On this tangle, it's not the poetic genres or the human consciousness, that provide the tragic existence, but the social existence, which over determine its different configurations.

Keywords: Materialism; Poetic Genres; Tragic.

\section{REFERÊNCIAS}

ADORNO, T. W (1970). Teoria estética. Lisboa: Edições 70.

ARISTÓTELES (1986). Poética. Trad. Eudoro de Souza. Lisboa: Imprensa Nacional/Casa da Moeda.

(1987). Arte retórica e poética. Trad. Antonio Pinto de Carvalho. Rio de Janeiro: Edições de Ouro.

BENJAMIN, W. (2011). Origem do drama trágico alemão. Trad. João Barrento. São Paulo: Autêntica.

BORHEIM, G. A. (1975) O sentido e a máscara. São Paulo: Perspectiva.

CANDIDO, A. (2006). Literatura e Sociedade. São Paulo: Ouro sobre azul.

HAUSER, A. (1994). História social da arte e da literatura. Trad. Álvaro Cabral. São Paulo: Martins Fontes.

HEGEL, G.W.F. (1993). Estética. Trad. Orlando Vitorino. Lisboa: Guimarães Editores.

LESKY, A. (1996). A tragédia grega. 3 ed. São Paulo: Perspectiva.

LUKACS, G. (2000). A teoria do romance. Trad. José Marcos Mariani de Macedo. Editora 34. 
SZONDI, P. (2004) Ensaio sobre o trágico. Trad. Pedro Siissekind. Rio de Janeiro: Jorge Zahar.

VERNANT, J. P. (1977). Mito e tragédia na Grécia antiga. Trad Anna Lia A. de Almeida Prado. São Paulo: Duas Cidades.

WILLIAMS, R. (2002). Tragédia moderna. Trad. Betina Bischof. São Paulo: Cosac \& Naify. 